\title{
Multi-Objective Optimization of Forth Flotation Process: An Application in Gold Ore
}

\author{
Wen Zhang ${ }^{1}$, Qinghe Yuan ${ }^{1,2, *}$, Shun Jia ${ }^{1,2, *}$, Zhaojun (Steven) $\mathrm{Li}^{3, *}$ and Xianhui Yin ${ }^{4}$ \\ 1 Department of Industrial Engineering, College of Energy and Mining Engineering, Shandong University of \\ Science and Technology, Qingdao 266590, China; zw1468038343@163.com \\ 2 National Demonstration Center for Experimental Mining Engineering Education, Qingdao 266590, China \\ 3 Department of Industrial Engineering \& Engineering Management, College of Engineering, Western New \\ England University, Springfield, MA 01119, USA \\ 4 College of Quality and Standardization, Qingdao University, Qingdao 266071, China; \\ qsyinxianhui@qdu.edu.cn \\ * Correspondence: yuan_qinghe@sina.com (Q.Y.); herojiashun@163.com (S.J.); zhaojun.li@wne.edu (Z.L.)
}

Citation: Zhang, W.; Yuan, Q.; Jia, S.; Li, Z.; Yin, X. Multi-Objective Optimization of Forth Flotation Process: An Application in Gold Ore. Sustainability 2021, 13, 8314.

https://doi.org/10.3390/su13158314

Academic Editor: Paolo Renna

Received: 11 June 2021

Accepted: 12 July 2021

Published: 26 July 2021

Publisher's Note: MDPI stays neutral with regard to jurisdictional claims in published maps and institutional affiliations.

Copyright: (c) 2021 by the authors. Licensee MDPI, Basel, Switzerland. This article is an open access article distributed under the terms and conditions of the Creative Commons Attribution (CC BY) license (https:// creativecommons.org/licenses/by/ $4.0 /)$.

\begin{abstract}
In order to improve production control ability in the gold ore flotation process, the output index in this process was studied. Flotation is an effective gold recovery process. Gold concentrate grade and gold recovery rate are the key output indicators of the flotation process. However, in the existing studies exploring the impact of parameter changes on the output indicators, the control ability of the output indicators is insufficient, and the interaction between variables is inadequately considered. Therefore, a multi-objective optimization model based on response surface methodology and the non-dominated sorting genetic algorithm-II (NSGA-II) is proposed in this paper. Firstly, the experiment was designed based on the Box-Behnken principle. Based on the experimental results, the interaction between variables was analyzed and the response polynomial was fitted. Secondly, a multi-objective optimization model was constructed, and the NSGA-II was used to solve the model. Finally, an example of gold ore flotation was used to verify the effectiveness of the method. The optimal solution was a gold concentrate grade of $75.46 \mathrm{~g} / \mathrm{t}$ and a gold recovery rate of $85.98 \%$.
\end{abstract}

Keywords: response surface methodology; NSGA-II; gold ore flotation process; multi-objective optimization

\section{Introduction}

With the continuous development of science and technology, gold has been widely used in communications, electronics, aviation, medicine, and other fields. The increase in demand for gold requires that all links in the gold mining process need to increase production capacity. Ore beneficiation is an indispensable part of the processing of mineral resources and occupies an important position in the process of mineral production [1]. Gravity separation, mercury mixing, flotation, and cyanidation are commonly used beneficiation technologies for gold ore treatment [2]. Gold ore flotation is a method for separating ore by using the differences in the physical or the chemical properties of the ore surface. Gold ore flotation is a continuous, complex industrial process with strong nonlinearity, strong coupling, multiple inputs, and multiple outputs. Knowing how to accurately derive the best input variables in a complex industrial process is very important to achieving the required final product quality [3]. In recent years, the process parameters and the dosage of reagents in the flotation process have been extensively studied [4]. Although extensive research has been carried out on the gold ore flotation process, no single study exists which adequately covers the interactions among parameters. The prior optimization method was used to study the flotation process, and the output index was obtained through experiments after the parameters changed. One major drawback of this approach is that the output control of the flotation process is not conductive. The research would have 
been more relevant if the interaction between parameters and the multi-objective optimization of variables in the flotation process were considered simultaneously. Therefore, a multi-objective optimization model of the gold ore flotation process based on response surface methodology and the NSGA-II is proposed in this paper. Firstly, according to the principle of the Box-Behnken experiment, the experimental design was carried out, and the experiment results were analyzed by variance and fitted with a regression equation. Secondly, a multi-objective optimization model was constructed, and the NSGA-II was used to solve the multi-objective optimization model. Finally, the optimization effect was verified by experiments. The contributions of this article are as follows: (1) The interaction between parameters in the flotation process is considered, and the accuracy of the optimization model is improved. (2) Multi-objective optimization is carried out for the flotation process of gold mining, and, considering the two output indexes of gold recovery and gold concentrate grade, the flotation capacity of gold mining is improved. (3) A reasonable determination of the flotation parameters improves the production control ability of the gold ore flotation process.

\section{Literature Review}

With the depletion of the world's mineral resources, the question of how to recover fine gold particles from various ores has become a problem that metallurgical workers and mineral processing workers have been concerned about for decades. The flotation process is an important part of gold mining. Domestic and foreign scholars have conducted in-depth research on the flotation process of gold mines. Forrest et al. [5] studied the effects of collector types and various operating variables on gold recovery. The results showed that the gold recovery rate is not affected by the $\mathrm{pH}$ value and increasing the collector concentration can increase the gold recovery rate to a certain extent. Chanturia et al. [6] studied the effect of xanthic acid and a new collector on gold ore flotation performance, and determined the selectivity characteristics of a nitrogen-containing agent and a phosphoruscontaining agent for gold. The results showed that the new optimized reagent mode can improve the gold recovery rate and the gold concentrate grade. Zhang et al. [7] studied the flotation of a copper-gold ore in tap water and in sea water in the presence of $10 \%$ bentonite. The results showed that bentonite has a certain influence on the flotation of copper and gold in tap water, but the influence in seawater was reduced. In recent years, domestic and foreign scholars have conducted extensive research on the influence of a single factor on the gold ore flotation process. Guo et al. [8] used surface-enhanced Raman spectroscopy to study the effect of zinc cyanide on the flotation of gold from pyrite. The results showed that free cyanide has no inhibition effect on gold ore flotation, but zinc cyanide with a ratio of $\mathrm{CN} 2$ to $\mathrm{Zn}$ has an inhibitory effect on gold ore flotation. Liu et al. [9] calculated the entrainment degree in order to find out the causes of the poor flotation of high clay content gold ores, and used lignosulfonate based biopolymer to alleviate the negative impact of clay minerals on the flotation of high clay content gold ores. It was found that the lignosulfonate-based biopolymer significantly increased the gold grade and recovery by reducing the mechanical entrainment rate and the pulp viscosity. Matveeva et al. [10] studied the complex adsorption capacity of cyclic amine and aliphatic amine dithiocarbamate in gold ore flotation. The results showed that under the conditions of low reagent consumption, a ring of amines and fatty amine salt dithiocarbamate raise the floatability of chalcopyrite by 1.5-2.0 times its original value, suggesting that ring amine and fatty amine salt dithiocarbamate in the low arsenic gold ore flotation of copper concentrate production has a good effect. The above research did not discuss the influence of the interaction between various factors in the gold ore flotation process on the process, only optimized the gold recovery rate or gold concentrate grade for a single objective, and did not involve multi-objective optimization problems. Therefore, this paper proposes a multiobjective optimization model based on response surface methodology and the NSGA-II. The gold recovery rate and gold concentrate grade are taken as the optimization objectives, and the parameters in the flotation process are taken as the optimization variables. The 
response surface methodology is used to analyze the interaction between the parameters, and a regression model is fitted. The NSGA-II is used to solve the model, in order to synchronously improve the gold recovery and the gold concentrate grade in the process of gold ore flotation.

\section{Methodology}

\subsection{Problem Description}

The main flotation processes of gold ore are one roughing process, one cleaning process, and two scavenging processes A flow chart of the flotation process is shown in Figure 1. The gold concentrate obtained from the flotation process is reground and classified, and then enters the cyanidation operation. The middling 1 , middling 2 , and middling 3 obtained in the flotation process return to the next round of flotation. Part of the tailings from the flotation process goes into the mine for filling, and the other part is pumped into the tailings pond. Taking the flotation process of quartz vein gold ore as the research object, three independent parameters that have an impact on the flotation process are selected as variables, including the fineness, the dosage of xanthate, and the dosage of QX-3 flotation oil. A multi-objective optimization model is constructed with gold concentrate grade and gold recovery rate as the optimization objectives.

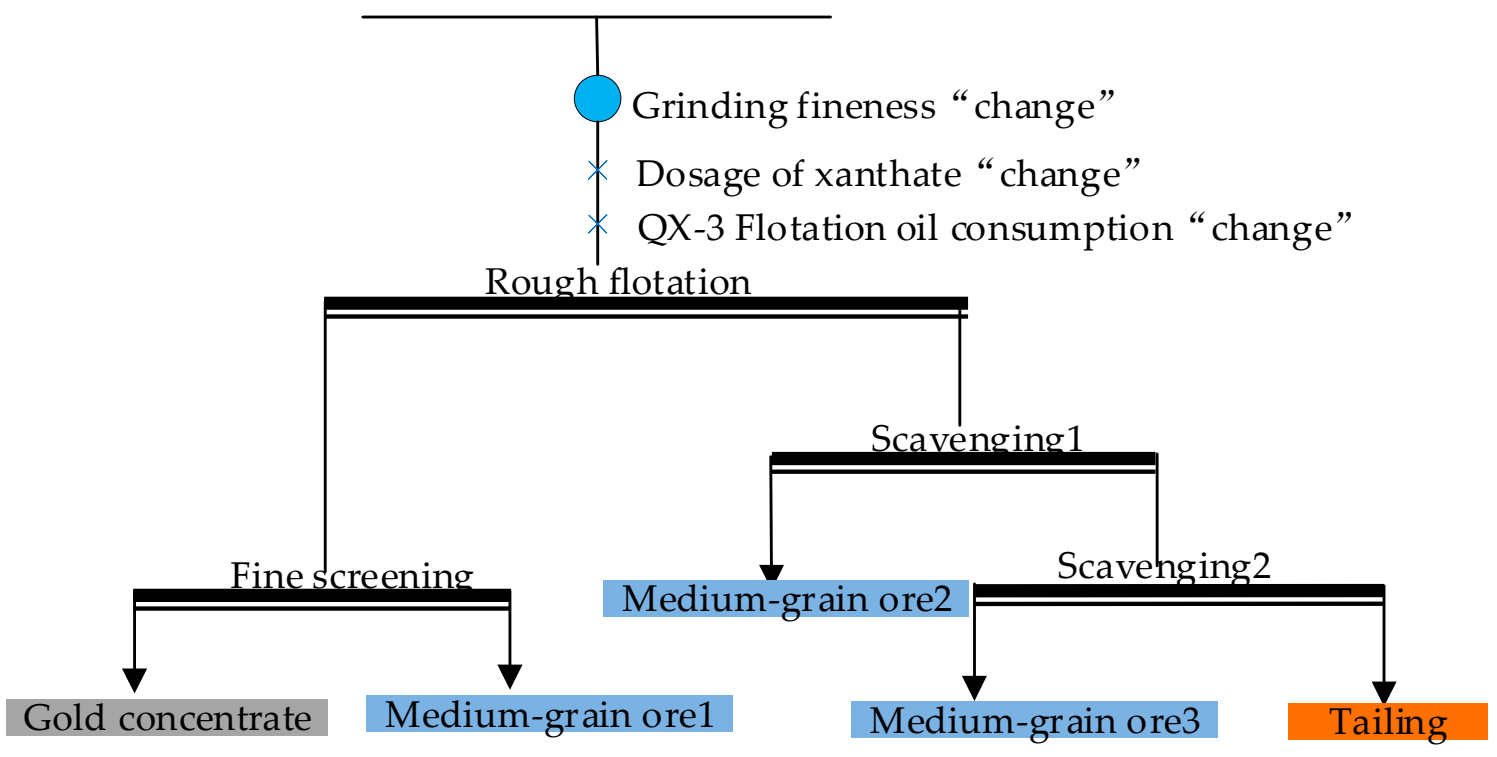

Figure 1. Flotation process flow chart.

The mineral sample used in the experiment is taken from a quartz vein type gold mine. The KYF4 type flotation machine, with an effective volume of $4 \mathrm{~m}^{3}$ and a production capacity of $4 \mathrm{~m}^{3} / \mathrm{min}$, is selected for the flotation process. The working principle of the flotation machine is that the impeller rotates to suck the pulp between the impeller blades, and the low-pressure air enters the air distributor in the impeller cavity. After the pulp and air are fully mixed in the transport zone, they are discharged from the periphery of the upper half of the impeller into the separation zone. The mineralized bubbles rise to the surface of the tank and flow into the foam layer. The pulp returns to the impeller area for recirculation or enters the lower tank through the circulation hole for sorting. A structural diagram of the flotation machine is shown in Figure $2 \mathrm{a}$, and a principle diagram of the flotation machine is shown in Figure $2 b$. The foaming agent used in the experiment is QX-3 Flotation oil consumption. The collector is xanthate, and foam flotation is adopted. 


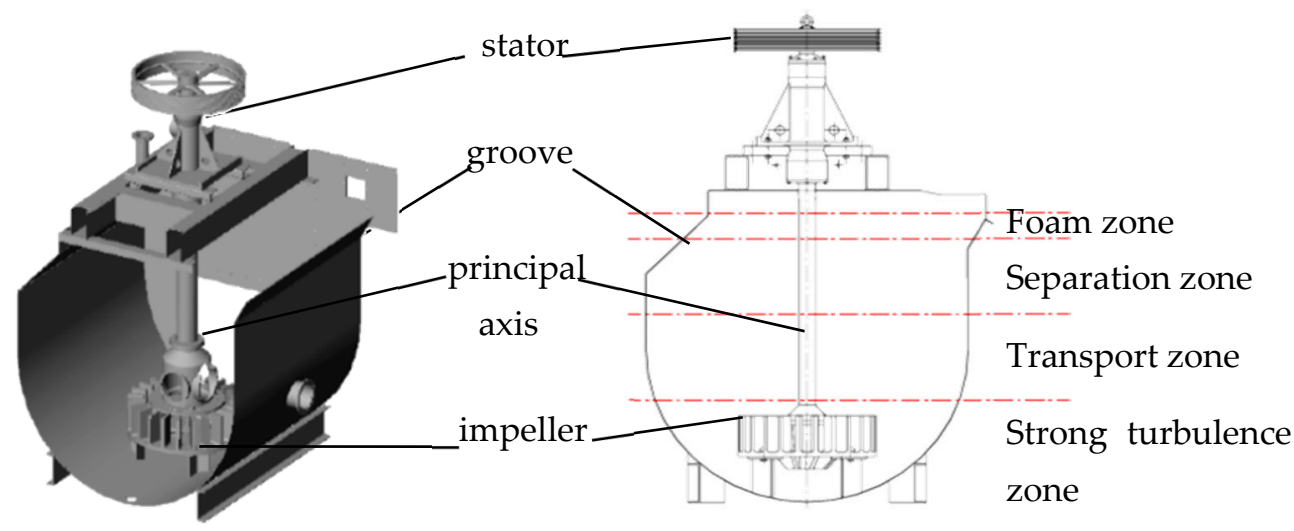

(a)

(b)

Figure 2. Flotation machine structure diagram and a principle diagram of the flotation machine. (a) Flotation machine structure diagram; (b) flotation machine principle diagram.

\subsection{Model Formulation}

Multi-objective optimization is the process of finding decision variables that satisfy constraints in order to make all objective functions have acceptable values [11]. In general, in multi-objective optimization problems, each objective function is mutually restricted. For multi-objective optimization problems, the solution is usually a set of non-inferior solutions, and the optimal solution needs to be evaluated by a multi-attribute optimization algorithm. The idea of a traditional multi-objective optimization algorithm is to transform the multi-objective problem into a single objective optimization problem. The simulation only produces one optimization solution at a time, and then obtains multiple different optimal solutions through multiple simulations [12]. The multi-objective optimization method proposed in this paper is to combine the response surface methodology and the NSGA-II algorithm, and considers the interaction between parameters in the flotation process to obtain the optimal process parameters and the optimal output index in the gold ore flotation process. The framework of this method is shown in Figure 3.
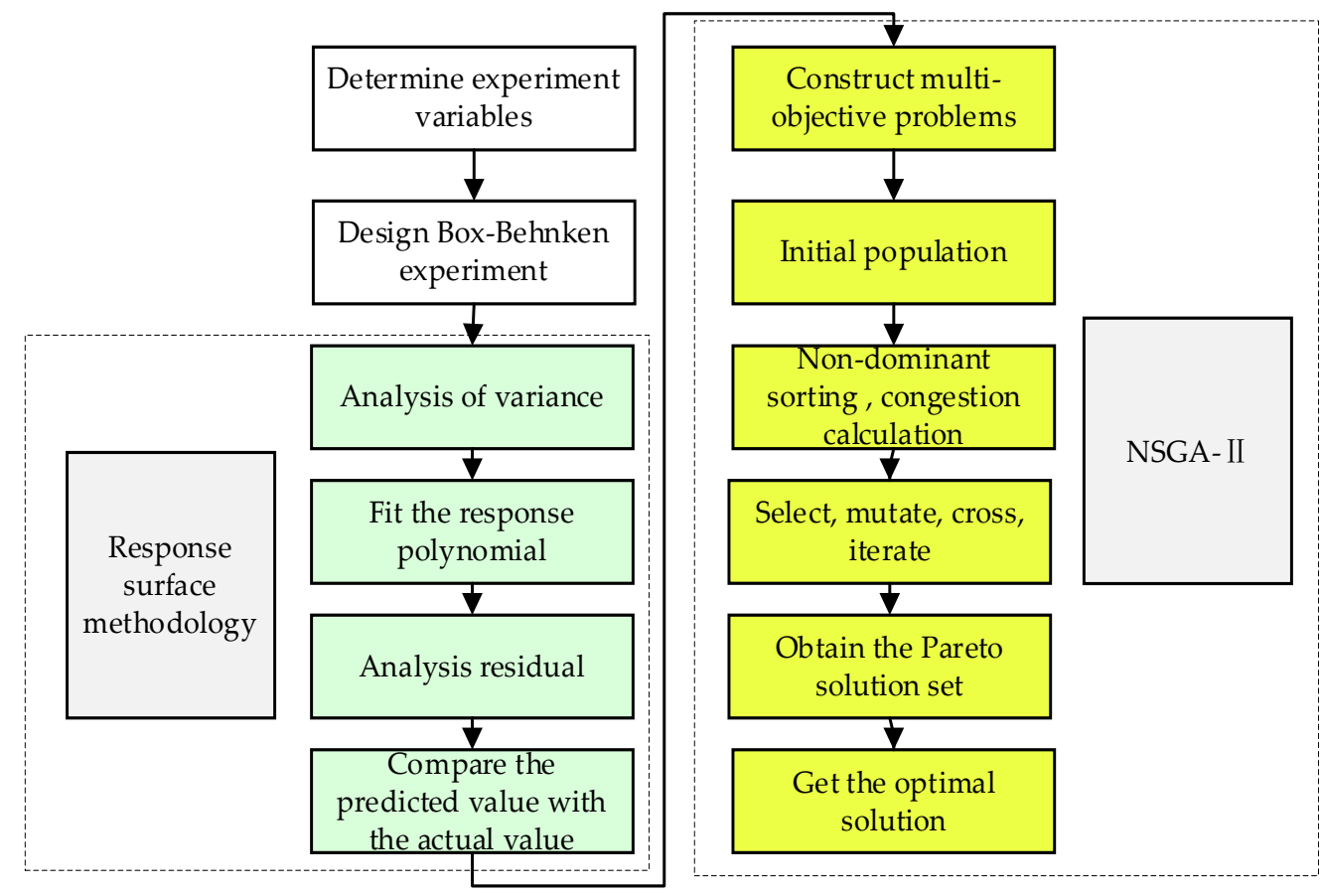

Figure 3. Optimization flow chart. 
Firstly, the key input variables and output variables are determined according to the working mechanism of the flotation process, and the multi-objective optimization problem in gold flotation process is determined, including objective function and design variables. Then, according to the Box-Behnken principle, the independent variables input in the flotation process are designed with three factors and three levels, and the corresponding experiments are carried out to obtain the response of the gold concentrate grade and the gold recovery rate. A multi-objective optimization model is built, and the NSGAII algorithm is used to solve the optimization model. Finally, the optimal plan of the gold concentrate grade and the gold recovery is obtained. In this paper, aiming at the multi-objective optimization problem in the process of gold flotation, the response surface method is used to construct a response surface model with gold concentrate grade and gold recovery rate as the response values, and the selection fineness $x_{1}$, xanthate dosage $\mathrm{x}_{2}$, and QX-3 flotation oil dosage $\mathrm{x}_{3}$ as variables. A multi-objective optimization model is proposed as shown in Equation (1):

$$
\begin{aligned}
& \operatorname{MaxY}(x)=\left(y_{1}(x), y_{2}(x)\right)^{T} \\
& l_{i} \leq x_{i} \leq u_{i}, i=1,2,3
\end{aligned}
$$

where $l_{i}$ is the lower limit of the $i$ influencing factor, and $u_{i}$ is the upper limit of the $i$ influencing factor.

\subsection{Solving Methodology}

\subsubsection{Response Surface Methodology}

Response surface methodology is an optimization method based on statistics. The response surface methodology can effectively solve the multi-variable problem. The surface model is established by combining mathematical and statistical methods to evaluate the interaction among the parameters, so as to determine the best level of the parameters [13]. Response surface methodology has the advantages of good model stability and requiring fewer experiments [14]. The functional relationship between the parameters and the response values can be fitted with a small number of experiment groups, and the interaction among parameters can be displayed at the same time [15]. Response surface methodology is widely used to clarify the interaction between reaction parameters [16]. According to the response surface methodology, the second-order response polynomial is constructed as shown in Equation (2):

$$
y_{i}=\beta_{0}+\sum_{i=1}^{n} \beta_{i} x_{i}+\sum_{i=1}^{n} \beta_{i i} x_{i}^{2}+\sum_{i>j}^{n} \beta_{i j} x_{i} x_{j}
$$

where $y_{i}$ is the optimization index in the flotation process, $x_{i}$ is an independent variable in the flotation process, $\beta_{0}$ is the constant coefficient, $\beta_{\mathrm{i}}$ is the coefficient of the linear term, $\beta_{\mathrm{ij}}$ is the second order interaction coefficient, and $\beta_{\mathrm{ii}}$ is the quadratic coefficient.

The experimental design table, based on the principle of Box-Behnken central composite design, is shown in Table 1. The Box-Behnken experimental design can reduce the number of required experiments, thereby reducing the workload of researchers and reducing the cost of experiments [17].

According to the experiment design table, the experiment is carried out and the output indexes of the flotation process are obtained. The variance analysis table is made according to the response data. The significance of the model is judged according to the variance analysis table. The degree of fit between the model and the test is judged according to the lack of fit item. The interaction between parameters is evaluated based on the response surface diagrams. Residual diagrams are drawn to analyze the suitability of the model. The accuracy of the regression model is judged by a comparison between the predicted value and the actual value. 
Table 1. The units and levels of various parameters.

\begin{tabular}{cccccc}
\hline Code Name & Parameter & Unit & Low Level & Medium Level & High Level \\
\hline $\mathrm{x}_{1}$ & Grinding fineness & $\%$ & 50 & 53 & 56 \\
$\mathrm{x}_{2}$ & Xanthate dosage & $\mathrm{g} / \mathrm{t}$ & 84 & 85 & 86 \\
$\mathrm{x}_{3}$ & QX-3 flotation oil & $\mathrm{g} / \mathrm{t}$ & 23 & 25 & 27 \\
& Consumption & & & & \\
\hline
\end{tabular}

\subsubsection{NSGA-II Algorithm}

The NSGA algorithm is a multi-objective optimization strategy based on the basic genetic algorithm. The difference between this algorithm and the traditional genetic algorithm is that it is hierarchized according to the dominance relationship between individuals before the selection operator is executed [18]. The NSGA-II algorithm is an improvement of the NSGA algorithm proposed by k-Deb in 2002, which solves the defects of the high computational complexity of the NSGA algorithm and the need to specify shared parameters [19]. The NSGA-II algorithm uses the dominance sorting and crowding distance [20] to give the algorithm the ability to approximate the optimal Pareto frontier, and to ensure that the obtained Pareto optimal solution has good generalization.

The NSGA-II algorithm can effectively solve multi-objective optimization problems. Compared with the NSGA, the NSGA-II has made improvements, and proposed a fast non-dominated sorting algorithm [21]. On the one hand, the computational complexity is reduced, and on the other hand, the parent population and the offspring population are merged, so that the next generation population is selected from a double space, thereby retaining all the best individuals. The elite strategy is introduced in the algorithm [22]. It ensures that some excellent individuals will not be discarded in the evolution process, thus improving the accuracy of the optimization results. The implementation process of the NSGA-II algorithm is shown in Figure 4. The adoption of crowding degree and crowding comparison operators not only overcomes the disadvantage of sharing parameters that need to be artificially specified in the NSGA, but also ensures the diversity of the population [23].

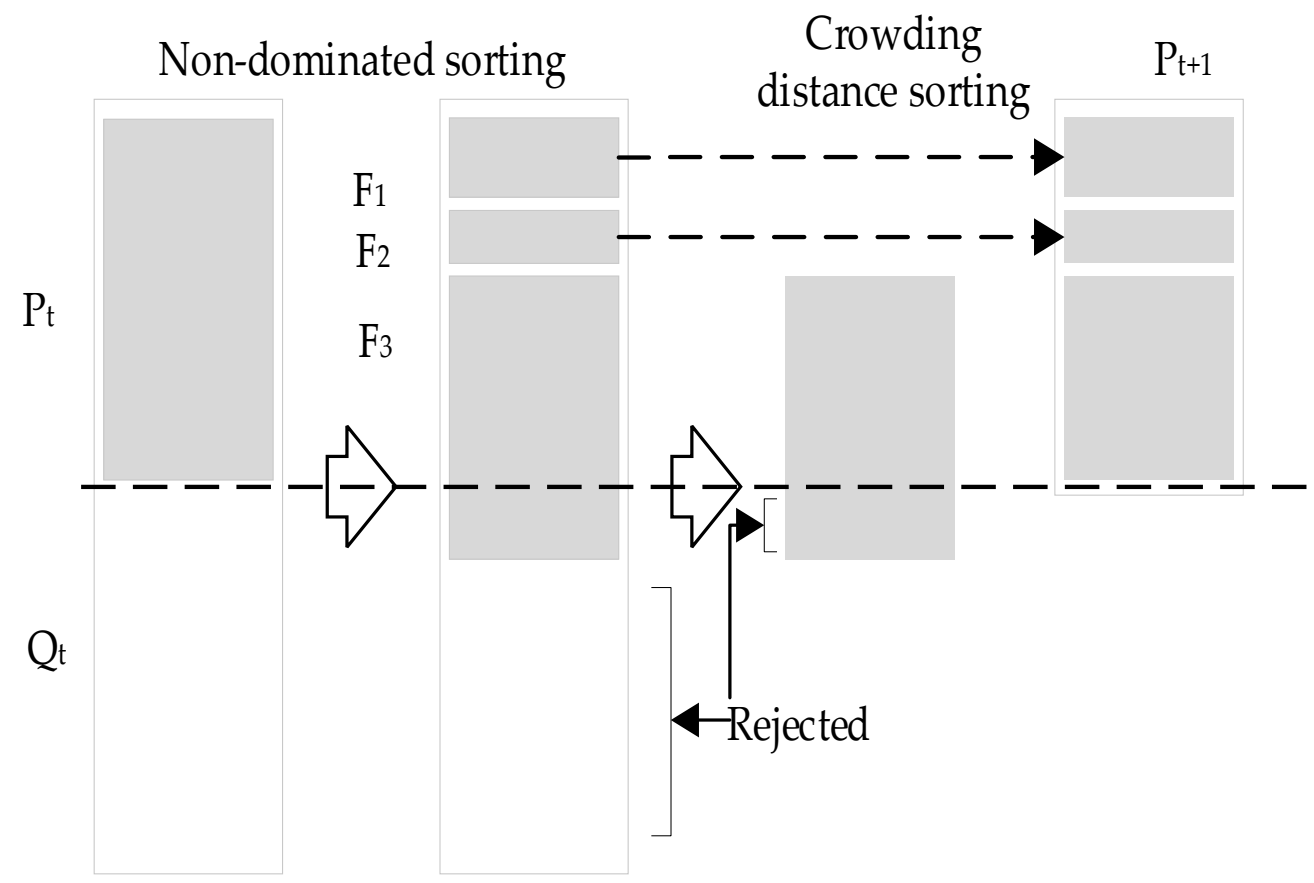

Figure 4. Algorithm implementation process diagram. 
The NSGA-II algorithm can be carried out according to the following steps:

1. $\quad N$ initial string structure data are generated randomly, and all the string structure data are uniformly distributed in the whole search space. $N$ individuals constitute a group, $\mathrm{P}_{0}$, and the NSGA-II starts its evolution with the $N$ string structure data as the initial point.

2. The initial population is taken as the parent population, and the offspring population, $\mathrm{Q}_{0}$, is obtained through genetic operators. Its population size is also $N$. The parent population and the offspring population are combined into a $2 \mathrm{~N}$ synthetic population, $\mathrm{P}_{\mathrm{t}}$, for fast non-dominated sorting, and reclassify all individuals in $\mathrm{P}_{\mathrm{t}}$ according to the non-dominated sequence number to obtain grades $\mathrm{F}_{1}, \mathrm{~F}_{2}$, and $\mathrm{F}_{3}$.

3. The individual local crowding distance of each non-dominated layer is calculated and sorted. According to the sorting results, $N$ individuals are selected as the new parent population, $\mathrm{P}_{t+1}$. A new offspring population, $\mathrm{Q}_{t+1}$, is generated by genetic operator. When the algorithm reaches the maximum number of iterations, the Pareto front solution is output and the algorithm ends. The flow chart of the NSGA-II algorithm is shown in Figure 5.
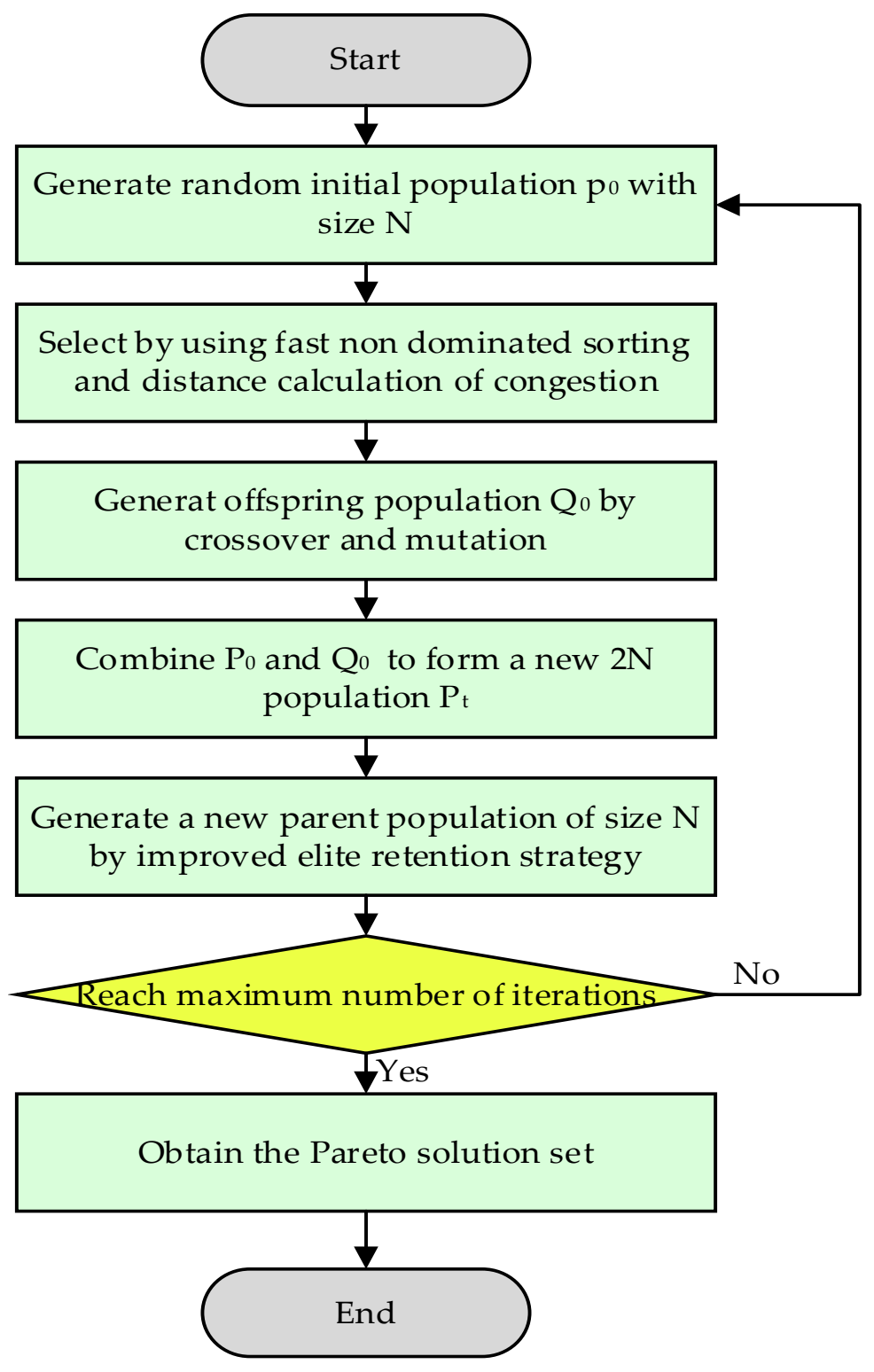

Figure 5. Multi-objective optimization process based on the NSGA-II. 
The optimal Pareto solution set can be obtained by the NSGA-II algorithm. In order to select the optimal solution from Pareto front set, a fuzzy membership function is used. The degree of membership reflects the degree of satisfaction of the decision-maker for the optimization of the objective, and the fuzzy membership of each objective function is integrated to find the optimal solution [24]. First, the Pareto solution set is traversed, and Equation (3) is used to calculate the membership of the $i$-th objective function in the $k$-th solution in the Pareto solution set.

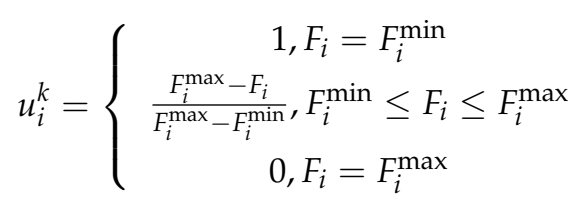

where: $F_{i}$ is the value of the objective function $i$, and $F_{i}{ }^{\min }$ and $F_{i}{ }^{\max }$ are the upper and lower limits of the objective function value, respectively. The weight value is set according to the actual situation, and the weighted value of the membership degree of the optimal solution of the multi-objective function is calculated [25]. The Pareto solution set corresponding to the maximum value obtained is the optimal solution. In this paper, equal weights are set, and the calculation expression is as shown in Equation (4).

$$
u^{k}=\frac{\sum_{i=1}^{N_{o b j}} \lambda_{i} u_{i}^{k}}{\sum_{k=1}^{N_{p}} \sum_{i=1}^{N_{o b j}} \lambda_{i} u_{i}^{k}}, k=1,2, \cdots, N_{p}
$$

where: $N_{p}$ is the number of solutions in the Pareto solution set; $\lambda_{i}$ is the value weight of the objective function $i ; N_{o b j}$ is the number of objective functions; and $u_{i}{ }^{k}$ is the value of the membership function.

\section{Case Study}

\subsection{Introduction of Xincheng Gold Ore and Experiment Design}

Xincheng Gold Ore was founded in 1975 and is located in Jincheng Town, Laizhou City, Jiaodong Peninsula. The working scope of Xincheng Gold Ore includes mining operations, ore flotation operations, and tailings storage. The mine covers an area of 3.94 square $\mathrm{km}$, with mining depths ranging from 26 to $1530 \mathrm{~m}$. Based on the expansion of the existing mineral processing workshop, the mineral processing scale reaches 6000 tons/day, and the final mineral processing product is gold concentrate. Xincheng Gold Ore, belonging to Shandong Gold Mining Co., Ltd., Shandong, China, is a large, national gold production enterprise with a comprehensive production capacity of mining, ore flotation, and smelting. Xincheng Gold Ore has advanced production technology and excellent production equipment. The KYF-4 flotation machine used in ore flotation is shown in the Figure 6. At present, the stability of the flotation process is poor. In order to improve the production control ability of the flotation process, the optimization of the flotation process must be considered.

The experimental design was based on the Box-Behnken principle. In this experiment, 17 experiment points, 12 analysis points, and 5 center points were designed to estimate the error. Industrial production was carried out according to the experiment design, and the experiment data were obtained. The results are shown in Table 2. 


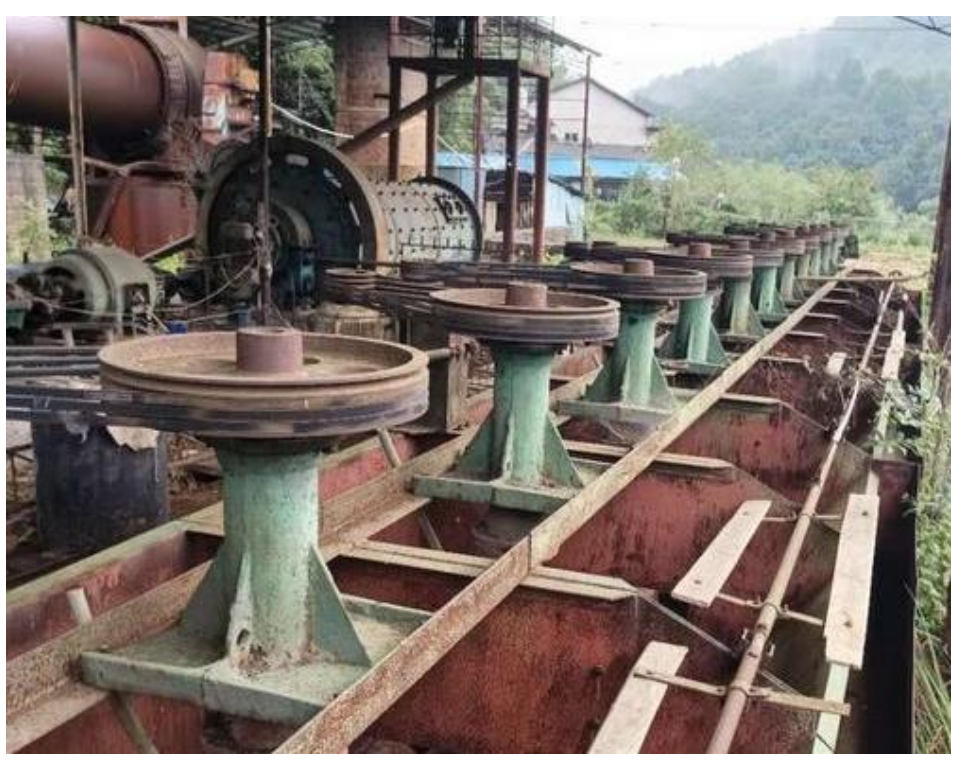

Figure 6. KYF-4 flotation machine.

Table 2. Experimental design table.

\begin{tabular}{ccccccc}
\hline Std & Run & $\mathbf{X}_{\mathbf{1}} \mathbf{\%}$ & $\mathbf{X}_{\mathbf{2}} \mathbf{g} / \mathbf{t}$ & $\mathbf{X}_{\mathbf{3}} \mathbf{g} / \mathbf{t}$ & Gold Recovery Rate $\%$ & Gold Concentrate Grade $\mathbf{g} / \mathbf{t}$ \\
\hline 1 & 3 & 50 & 84 & 25 & 86.15 & 72.79 \\
\hline 2 & 4 & 56 & 84 & 25 & 85.96 & 75.42 \\
\hline 3 & 7 & 50 & 86 & 25 & 86.14 & 64.81 \\
\hline 4 & 12 & 56 & 86 & 25 & 85.55 & 71.92 \\
\hline 5 & 1 & 50 & 85 & 23 & 86.03 & 74.38 \\
\hline 6 & 11 & 56 & 85 & 23 & 85.72 & 68.81 \\
\hline 7 & 5 & 50 & 85 & 27 & 85.98 & 67.72 \\
\hline 8 & 14 & 56 & 85 & 27 & 86.35 & 66.56 \\
\hline 9 & 6 & 53 & 84 & 23 & 86.02 & 75.29 \\
\hline 10 & 8 & 53 & 86 & 23 & 85.94 & 65.22 \\
\hline 11 & 10 & 53 & 84 & 27 & 86.01 & 74.99 \\
\hline 12 & 17 & 53 & 86 & 27 & 86.07 & 71.91 \\
\hline 13 & 2 & 53 & 85 & 25 & 85.95 & 67.52 \\
\hline 14 & 16 & 53 & 85 & 25 & 86.28 & 75.85 \\
\hline 15 & 13 & 53 & 85 & 25 & 85.98 & 68.69 \\
\hline 16 & 9 & 53 & 85 & 25 & 85.84 & 72.31 \\
\hline 17 & 15 & 53 & 85 & 25 & 85.85 & \\
\hline
\end{tabular}

Note: The data in the table has been desensitized.

\subsection{Response Polynomial Fitting}

\subsubsection{Interaction Analysis of Gold Recovery Rate}

The variance analysis of the experiment results obtained in the flotation process was carried out, and the variance analysis table of gold recovery is shown in Table 3.

The coefficient of determination of the variance was $\mathrm{R}^{2}=98.76 \%$, which indicated that the established model could explain the change of $98.76 \%$ in the response value [26]. The lack of fit item reflects the degree of fit between the model and the experiment, that is, the degree of difference between the two [27]. Here, $p=0.9389>0.05$, and there was no mismatch factor, which could be used to predict the relationship between the three selected variables and gold recovery. According to the analysis, $x_{1}$ and $x_{3}$ were significant influencing factors, while the other factors had no significant influence on the model. The 
influence of each factor on the response value was as follows: $x_{3}>x_{1}>x_{2}$; the order of influence of the interaction term was $x_{1} x_{2}>x_{2} x_{3}>x_{1} x_{3}$; the influence order of quadratic term was $\mathrm{x}_{2}^{2}>\mathrm{x}_{1}^{2}>\mathrm{x}_{3}^{2}$.

Table 3. Analysis of the variance of gold recovery rate.

\begin{tabular}{ccccccc}
\hline Source & Sum of Squares & Df & Mean Square & F-Value & $p$-Value & Significance \\
\hline Model & 0.5367 & 9 & 0.0596 & 112.06 & $<0.0001$ & significant \\
\hline $\mathrm{x}_{1}$ & 0.0055 & 1 & 0.0055 & 10.36 & 0.0147 & significant \\
\hline $\mathrm{x}_{2}$ & 0.0021 & 1 & 0.0021 & 3.97 & 0.0866 & \\
\hline $\mathrm{x}_{3}$ & 0.2521 & 1 & 0.2521 & 473.65 & $<0.0001$ & significant \\
\hline $\mathrm{x}_{1} \mathrm{x}_{2}$ & 0.0729 & 1 & 0.0729 & 136.99 & $<0.0001$ & significant \\
\hline $\mathrm{x}_{1} \mathrm{x}_{3}$ & 0.0002 & 1 & 0.0002 & 0.4228 & 0.5363 & \\
\hline $\mathrm{x}_{2} \mathrm{x}_{3}$ & 0.0600 & 1 & 0.0600 & 112.80 & $<0.0001$ & significant \\
\hline $\mathrm{x}_{1}{ }^{2}$ & 0.0581 & 1 & 0.0581 & 109.24 & $<0.0001$ & significant \\
\hline $\mathrm{x}_{2}{ }^{2}$ & 0.0916 & 1 & 0.0916 & 172.14 & $<0.0001$ & significant \\
\hline $\mathrm{x}_{3}{ }^{2}$ & 0.0017 & 1 & 0.0017 & 3.16 & 0.1185 & \\
\hline Residual & 0.0037 & 7 & 0.0005 & & & \\
\hline Lack of Fit & 0.0003 & 3 & 0.0001 & 0.1275 & 0.9389 & significant \\
\hline Pure Error & 0.0034 & 4 & 0.0009 & & & \\
\hline Cor Total & 0.5404 & 16 & & & & \\
\hline Note The & & & &
\end{tabular}

Note: The coefficient of determination $\mathrm{R}^{2}=98.76 \%$.

In order to further analyze the influence of $x_{1}, x_{2}$, and $x_{3}$ on gold recovery rate, the interaction among the factors was analyzed in Figure 7 . The shape of the response surface in the $3 \mathrm{D}$ diagram reflects the relationship between the response variables and the parameters. The steeper the response surface is, the more significant the influence is [28]. It can be seen from Figure $7 \mathrm{a}, \mathrm{b}$ that when $\mathrm{x}_{2}$ increased gradually, the gold recovery rate increased first and then decreased. Figure $7 \mathrm{c}, \mathrm{d}$ shows that when $\mathrm{x}_{3}$ gradually increased, the gold recovery rate gradually increased, and the response surface changed faster along $x_{3}$ than along $x_{1}$. It can be seen from Figure $7 \mathrm{e}, \mathrm{f}$ that the gold recovery rate gradually increased with the increase of $x_{3}$. The analysis results were consistent with the model variance analysis results.

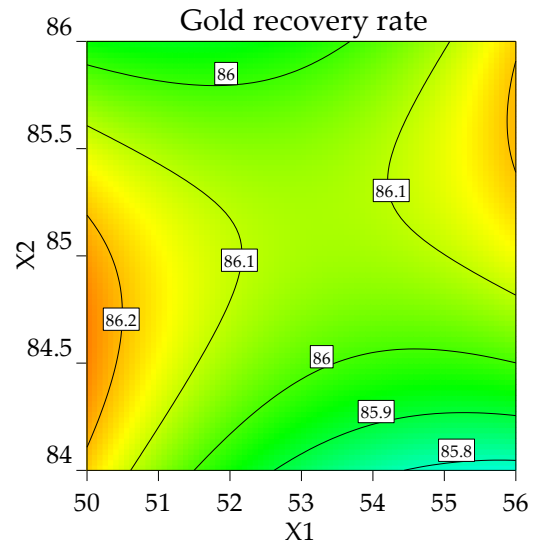

(a)

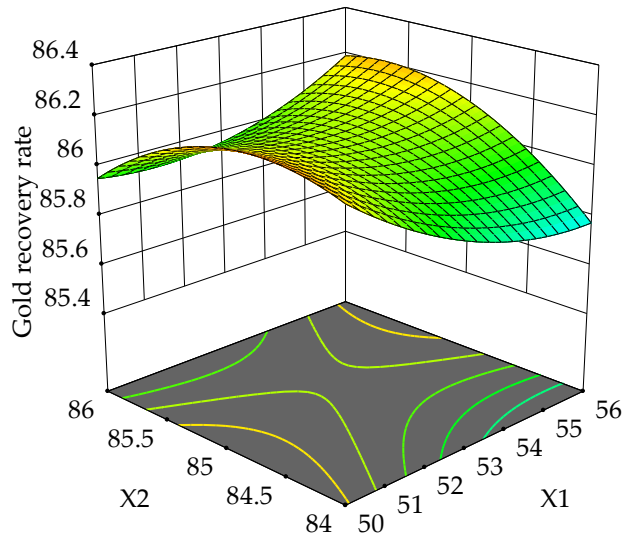

(b)

Figure 7. Cont. 


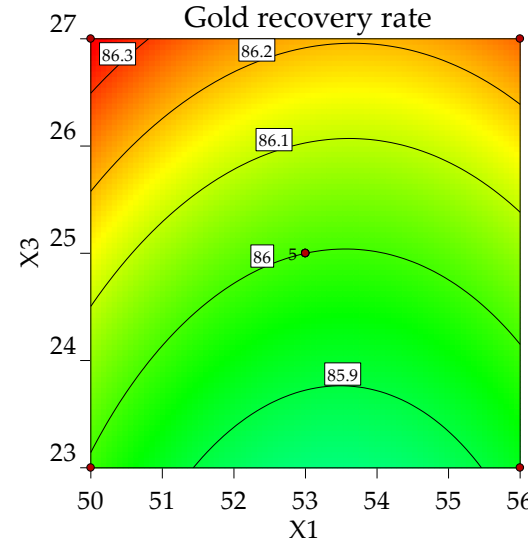

(c)

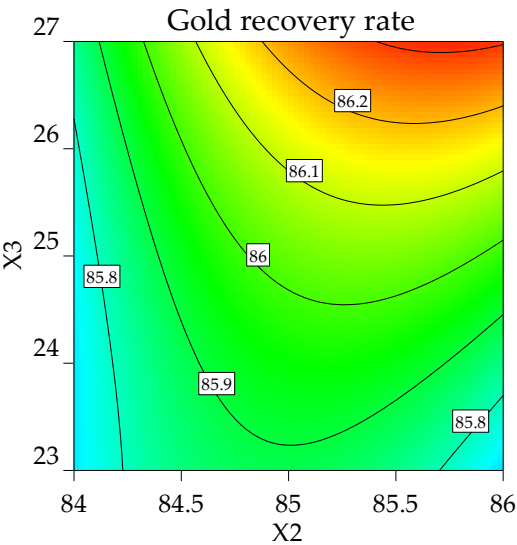

(e)

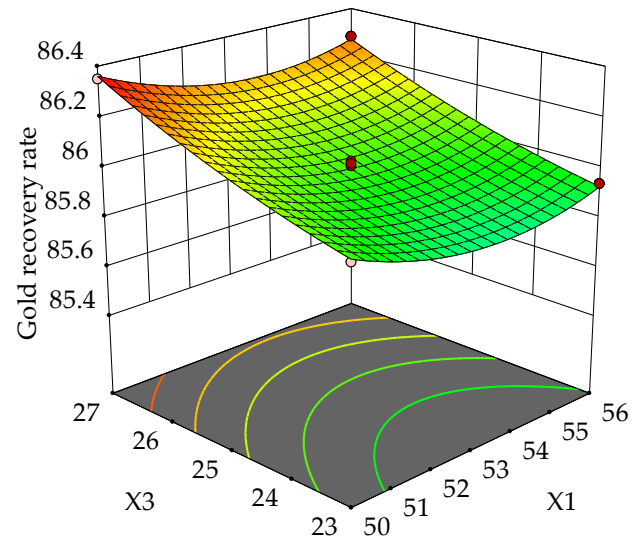

(d)

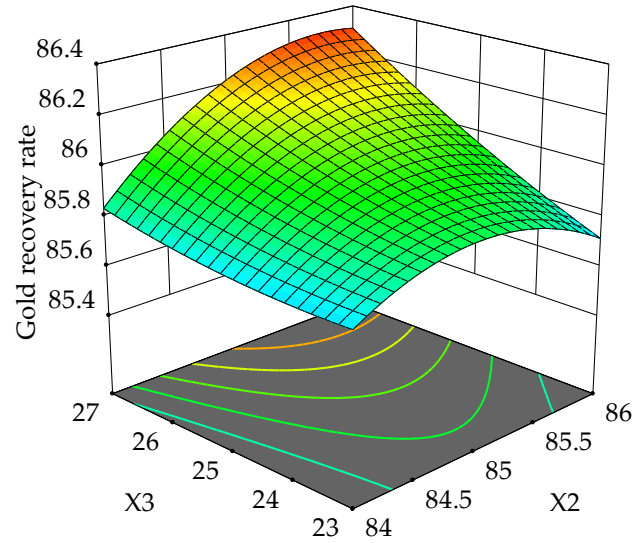

(f)

Figure 7. The individual and interactive effects of variables on gold recovery rate employing 2D and $3 D$ plots. $(\mathbf{a}, \mathbf{b})$ Effects of $x_{1}$ and $x_{2}$ on gold recovery rate; $(\mathbf{c}, d)$ effects of $x_{1}$ and $x_{3}$ on gold recovery rate; $(\mathbf{e}, \mathbf{f})$ effects of $x_{2}$ and $x_{3}$ on gold recovery rate.

\subsubsection{Interaction Analysis of Gold Concentrate Grade}

The experimental results were analyzed by variance analysis as shown in Table 4 .

Table 4. Variance analysis table of gold concentrate grade.

\begin{tabular}{ccccccc}
\hline Source & Sum of Squares & Df & Mean Square & F-Value & $p$-Value & Significance \\
\hline Model & 260.12 & 9 & 28.90 & 162.27 & $<0.0001$ & significant \\
\hline $\mathrm{x}_{1}$ & 5.27 & 1 & 5.27 & 29.56 & 0.0010 & significant \\
\hline $\mathrm{x}_{2}$ & 6.41 & 1 & 6.41 & 35.98 & 0.0005 & significant \\
\hline $\mathrm{x}_{3}$ & 4.85 & 1 & 4.85 & 27.24 & 0.0012 & significant \\
\hline $\mathrm{x}_{1} \mathrm{x}_{2}$ & 35.70 & 1 & 35.70 & 200.44 & $<0.0001$ & significant \\
\hline $\mathrm{x}_{1} \mathrm{x}_{3}$ & 1.51 & 1 & 1.51 & 8.49 & 0.0225 & significant \\
\hline $\mathrm{x}_{2} \mathrm{x}_{3}$ & 1.38 & 1 & 1.38 & 7.75 & 0.0271 & significant \\
\hline $\mathrm{x}_{1}{ }^{2}$ & 155.03 & 1 & 155.03 & 870.42 & $<0.0001$ & significant \\
\hline $\mathrm{x}_{2}{ }^{2}$ & 12.83 & 1 & 12.83 & 72.02 & $<0.0001$ & significant \\
\hline $\mathrm{x}_{3}{ }^{2}$ & 22.53 & 1 & 22.53 & 126.47 & $<0.0001$ & significant \\
\hline Residual & 1.25 & 7 & 0.1781 & & & \\
\hline Lack of Fit & 0.8643 & 3 & 0.2881 & 3.01 & 0.1572 & Not \\
\hline Pure Error & 0.3825 & 4 & 0.0956 & & & \\
\hline Cor Total & 261.36 & 16 & & & & \\
\hline Note: & & & &
\end{tabular}

Note: determine the coefficient $\mathrm{R}^{2}=98.79 \%$. 
The analysis of variance in Table 4 shows that $p<0.05$, indicating that the model was significant and there was a significant non-linear relationship between the response value and the variables. The determination coefficient $R^{2}$ of the equation was $98.79 \%$, which indicates that the established model could explain the change of $98.79 \%$ in the response value. The lack of fit was not significant at the $95 \%$ confidence interval level $(p=0.1572>0.05)$, that is, the degree of lack of fit of the equation was small, and it could actually be used to predict the situation between the selected three parameters and the gold concentrate grade. Linear model values $\left(\mathrm{x}_{1}, \mathrm{x}_{2}\right.$, and $\left.\mathrm{x}_{3}\right)$, quadratic model values $\left(\mathrm{x}_{1}{ }^{2}, \mathrm{x}_{2}{ }^{2}\right.$, and $\left.\mathrm{x}_{3}{ }^{2}\right)$ and interactive model values $\left(\mathrm{x}_{1} \mathrm{x}_{2}, \mathrm{x}_{1} \mathrm{x}_{3}\right.$, and $\left.\mathrm{x}_{2} \mathrm{x}_{3}\right)$ were significant, with $p<0.05$.

The response surface of the gold concentrate grade was plotted as shown in Figure 8. From Figure $8 \mathrm{a}, \mathrm{b}$ it can be seen that when $\mathrm{x} 1$ increased gradually, the grade of gold concentrate increased first and then decreased, and the response surface changed faster along the $\mathrm{x}_{1}$ direction than along the $\mathrm{x}_{2}$ direction. It can be seen from Figure $8 \mathrm{c}, \mathrm{d}$ that when $\mathrm{x}_{1}$ gradually increased, the gold concentrate grade first increased and then decreased. In Figure $8 \mathrm{e}, \mathrm{f}$ when $\mathrm{x}_{3}$ increased gradually, the gold concentrate grade increased first and then decreased, and the response surface changed faster along the $x_{3}$ direction than along the $\mathrm{x}_{2}$ direction.

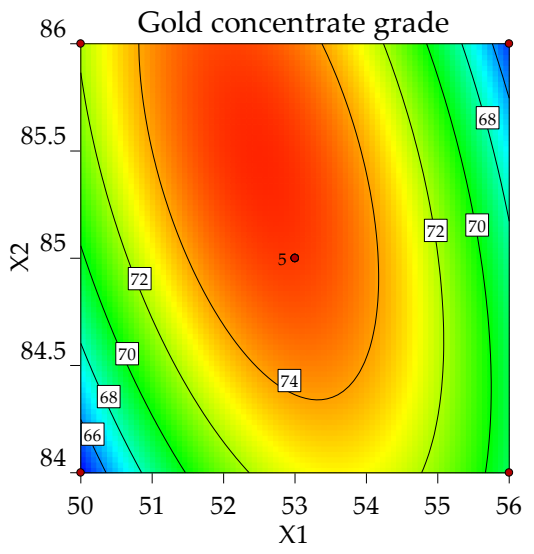

(a)

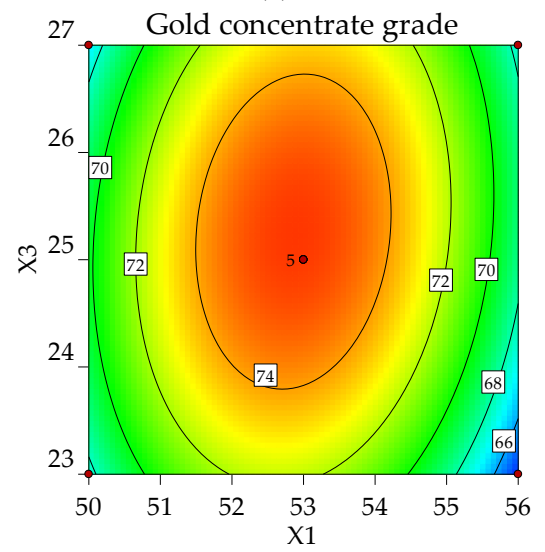

(c)

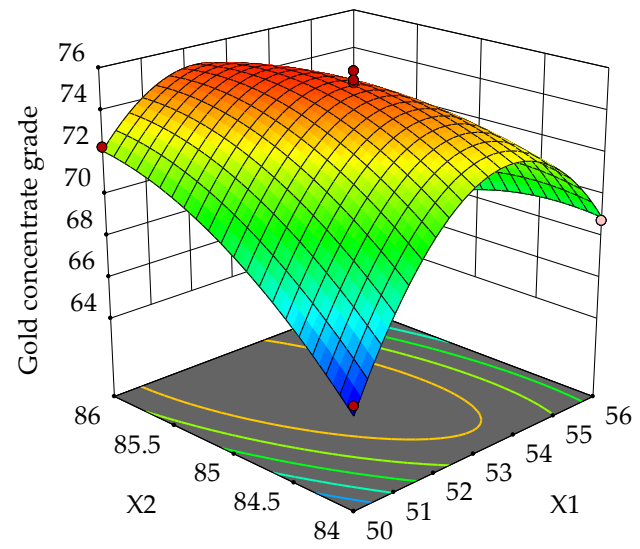

(b)

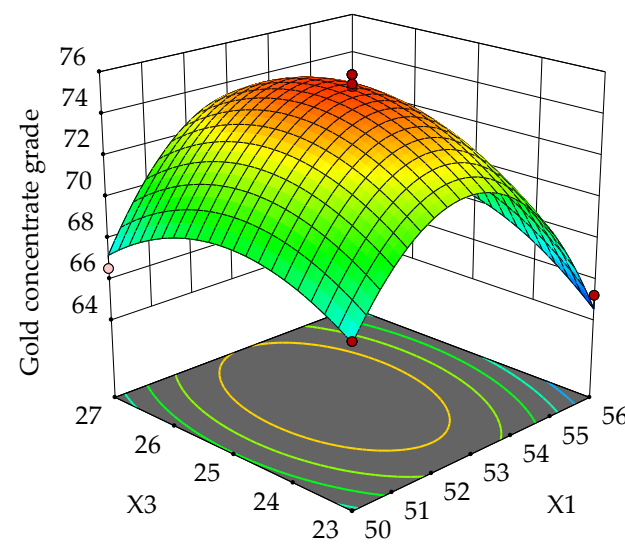

(d)

Figure 8. Cont. 


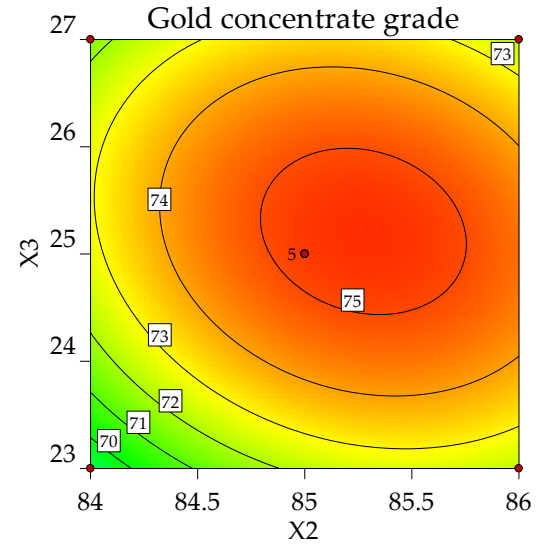

(e)

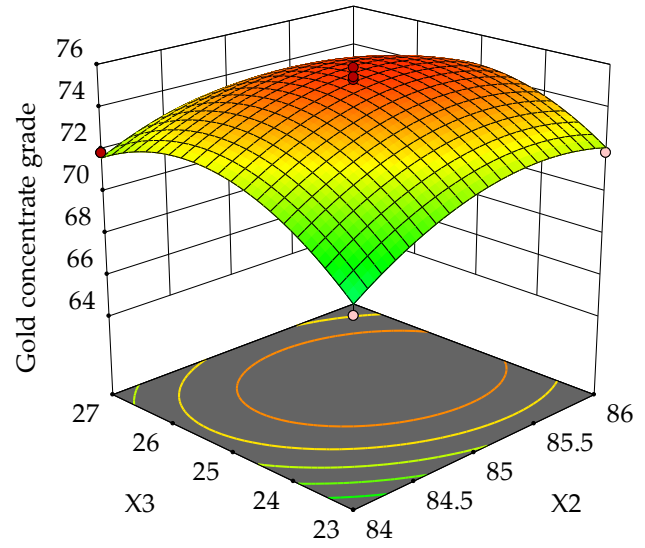

(f)

Figure 8. The individual and the interactive effects of variables on gold concentrate grade employing $2 \mathrm{D}$ and 3D plots. $(\mathbf{a}, \mathbf{b})$ Effects of $\mathrm{x}_{1}$ and $\mathrm{x}_{2}$ on gold concentrate grade; $(\mathbf{c}, \mathbf{d})$ effects of $\mathrm{x}_{1}$ and $\mathrm{x}_{3}$ on gold concentrate grade; $(\mathbf{e}, \mathbf{f})$ effects of $x_{2}$ and $x_{3}$ on gold concentrate grade.

A multivariate second-order model was used to fit the experimental results. After eliminating the insignificant variables, the model was modified, and the second-order response polynomial of the output gold recovery rate and the gold concentrate grade is shown in Equations (5) and (6):

$$
\begin{gathered}
\mathrm{y}_{1}=-664.5990-5.7517 \mathrm{x}_{1}+22.8383 \mathrm{x}_{2}-5.4575 \mathrm{x}_{3}+0.0533 \mathrm{x}_{1} \times \mathrm{x}_{2}-0.0012 \mathrm{x}_{1} \times \mathrm{x}_{3}+0.0613 \mathrm{x}_{2} \times \mathrm{x}_{3}+0.0117 \mathrm{x}_{1}{ }^{2} \\
-0.1600 \mathrm{x}_{2}{ }^{2}-0.0081 \mathrm{x}_{3}{ }^{2} \\
\mathrm{y}_{2}=-18168.9822+152.5749 \mathrm{x}_{1}+319.5029 \mathrm{x}_{2}+46.8798 \mathrm{x}_{3}-0.9958 \mathrm{x}_{1} \times \mathrm{x}_{2}+0.1442 \mathrm{x}_{1} \times \mathrm{x}_{3}-0.2938 \mathrm{x} \times \mathrm{x}_{3} \\
-0.6770 \mathrm{x}_{1}{ }^{2}-1.5205 \mathrm{x}_{2}{ }^{2}-0.5845 \mathrm{x}_{3}{ }^{2}
\end{gathered}
$$

\subsection{Response Surface Analysis}

Figure 9 shows the normal probability distribution of the residual difference between the gold recovery rate and the gold concentrate grade. What can be clearly seen in Figure 9 is that the residual was in a linear distribution. It shows that that the residual was in line with the normal distribution and the model had good adaptability [29]. Figure 10 shows the distribution of the predicted and the actual values of the gold recovery rate and the gold concentrate grade. The predicted and actual values in the two figures are evenly distributed on the straight line and its vicinity, which means the response surface of the regression of the model could produce more accurate results [30].

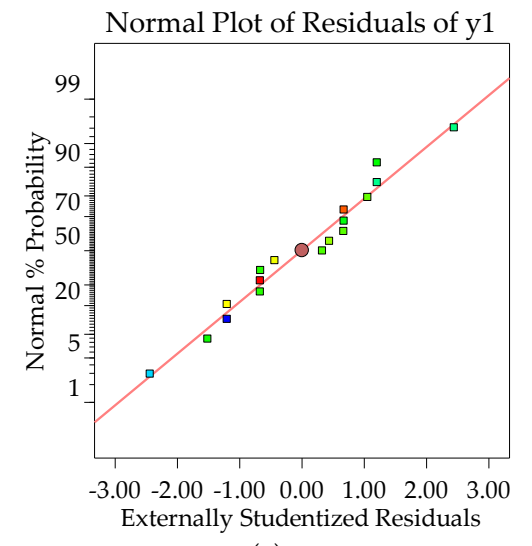

(a)

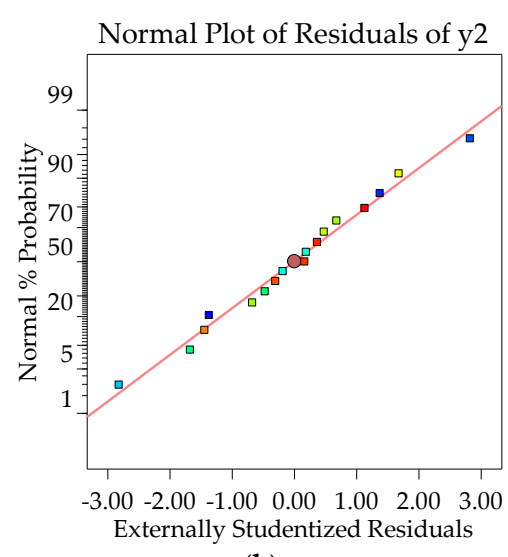

(b)

Figure 9. The normal distribution of residuals. (a) The gold recovery rate; (b) the gold concentrate grade. 


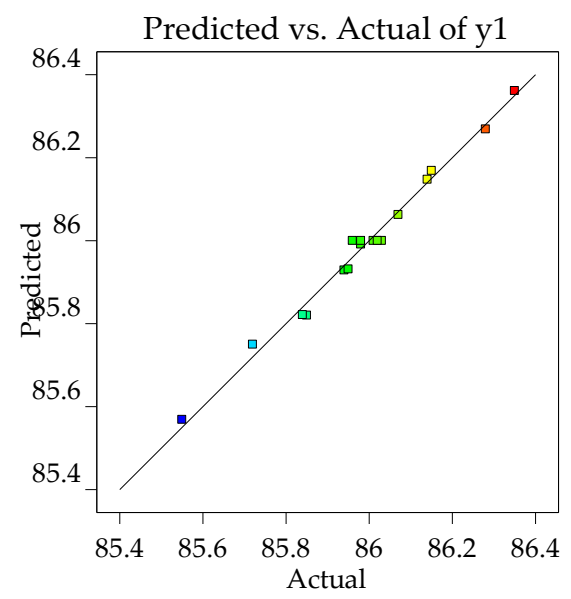

(a)

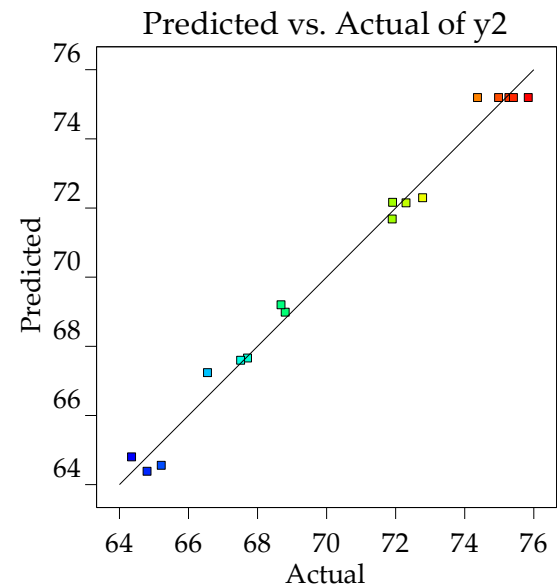

(b)

Figure 10. Comparison between the predicted and actual values. (a) The gold recovery rate; (b) the gold concentrate grade.

\subsection{Multi-Objective Optimization Based on NSGA-II Algorithm}

This method first used the NSGA-II to generate the Pareto front solution, and then used the fuzzy membership function to obtain the optimal compromise solution from the Pareto front solution set. The operating parameters were set In the optimization process, 175 solutions were obtained. Figure 11 depicts the two-dimensional Pareto front solution of multi-objective optimization. The as a population size of 500, iteration 500 times, a crossover probability of 0.3 , and a mutation probability of $1 / 17$. membership degree of the Pareto solution set was calculated and sorted. The solution with the highest membership degree was the optimal solution. The final optimal solution was a gold concentrate grade of $85.98 \mathrm{~g} / \mathrm{t}$, and a gold recovery rate of $75.46 \%$, as shown in the black spot in Figure 11 .

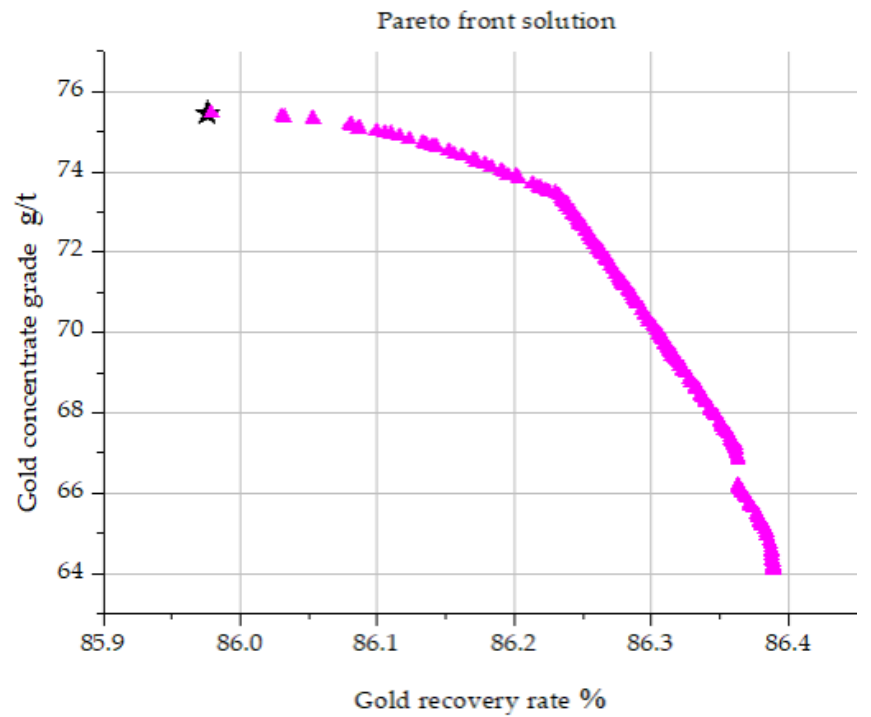

Figure 11. Two dimensional Pareto front solution considering two objectives.

\subsection{Verification Experiment}

The optimal solution obtained by the NSGA- II was verified by the experiments, and the quality indexes are shown in Table 5. 
Table 5. The verification experiment.

\begin{tabular}{cccccc}
\hline & $\begin{array}{c}\text { The Fineness of } \\
\text { Milling } \%\end{array}$ & Xanthate Dosage g/t & $\begin{array}{c}\text { QX-3 Flotation Oil } \\
\text { Consumption } \mathbf{g} / \mathbf{t}\end{array}$ & Gold Recovery Rate \% & $\begin{array}{c}\text { Gold Concentrate } \\
\text { Grade } \mathbf{g} / \mathbf{t}\end{array}$ \\
\hline Theoretical value & 52.52 & 85.44 & 25.11 & 85.98 & 75.46 \\
Experimental value & 52.52 & 85.44 & 25.11 & 86.32 & 75.89 \\
\hline
\end{tabular}

\section{Conclusions}

Improving the production capacity of the flotation process is crucial to the gold mining process. The flotation process of gold ore involves the determination of many operation parameters. However, it only depends on single factor experiments to solve the problem of parameter optimization in the flotation process, ignoring the interaction between parameters, which limits the production capacity of the gold ore flotation process. This paper presents a multi-objective optimization model based on response surface methodology and the NSGA-II algorithm. Firstly, the second-order response polynomials of the gold concentrate grade and the gold recovery rate were fitted by a variance analysis of the experimental data. Secondly, on the basis of the second-order response polynomial, the NSGA-II was used for multi-objective optimization. Finally, the multi-objective optimal solution was obtained. In this paper, the multi-objective optimization problem in the flotation process of quartz vein type gold ore was studied, and the optimal combination of various parameters in the flotation process was obtained. This paper carried out flotation experiments for a single type of equipment. On the basis of this research, the more complex multi-equipment flotation system will be further discussed in the future.

Author Contributions: Conceptualization, W.Z. and S.J.; methodology, Q.Y.; software, Z.L.; validation, W.Z., S.J. and Q.Y.; formal analysis, X.Y.; investigation, W.Z.; resources, S.J.; data curation, Q.Y.; writing —original draft preparation, W.Z.; writing—review and editing, W.Z.; visualization, S.J.; supervision, X.Y.; project administration, Q.Y.; funding acquisition, X.Y. All authors have read and agreed to the published version of the manuscript.

Funding: This research was funded by the National Natural Science Foundation of China, grant number 71971130;71701113, by the Project of Shandong Province Higher Educational Science and Technology Program, grant number J17KA167, and by the SDUST Research Fund, grant number $2018 Y$ YJH103.

Institutional Review Board Statement: Not applicable.

Informed Consent Statement: Not applicable.

Data Availability Statement: Not applicable.

Acknowledgments: We sincerely thank the anonymous reviewers for their helpful and constructive suggestions and the editors for their careful and patient work.

Conflicts of Interest: The authors declare no conflict of interest.

\section{References}

1. Liang, G.; Zhao, Q.; Liu, B.; Du, Z.; Xia, X. Treatment and reuse of process water with high suspended solids in low-grade iron ore dressing. J. Clean. Prod. 2021, 278, 123493. [CrossRef]

2. Liu, R.; Qin, W.; Jiao, F.; Wang, X.; Gong, M.; Yang, Y.; Pei, B.; Lai, C. Enhanced flotation of refractory gold ore by using sulfur-oil agglomeration with $\left(\mathrm{NH}_{4}\right)_{2} \mathrm{~S}_{2} \mathrm{O}_{3}$ as regulator in weak acidic pulp. Miner. Eng. 2016, 93, 24-31. [CrossRef]

3. Yin, X.; Niu, Z.; He, Z.; Li, Z.; Lee, D. An integrated computational intelligence technique based operating parameters optimization scheme for quality improvement oriented process-manufacturing system. Comput. Ind. Eng. 2020, 140, 106284. [CrossRef]

4. Asamoah, R.; Skinner, W.; Addai-Mensah, J. Alkaline cyanide leaching of refractory gold flotation concentrates and bio-oxidised products: The effect of process variables. Hydrometallurgy 2018, 179, 79-93. [CrossRef]

5. Forrest, K.; Yan, D.; Dunne, R. Optimisation of gold recovery by selective gold flotation for copper-gold-pyrite ores. Miner. Eng. 2001, 14, 227-241. [CrossRef]

6. Chanturia, V.; Nedosekina, T.V.; Gapchich, A.O. Improving gold flotation selectivity by using new collecting agents. J. Min. Sci. 2012, 48, 1031-1038. [CrossRef] 
7. Zhang, M.; Peng, Y.; Xu, N. The effect of sea water on copper and gold flotation in the presence of bentonite. Miner. Eng. 2015, 77, 93-98. [CrossRef]

8. Guo, B.; Peng, Y.; Mai, Y. The effect of zinc cyanide on the flotation of gold from pyritic ore. Miner. Eng. 2016, 85, 106-111. [CrossRef]

9. Liu, S.; Chen, X.; Lauten, R.A.; Peng, Y.; Liu, Q. Mitigating the negative effects of clay minerals on gold flotation by a lignosulfonatebased biopolymer. Miner. Eng. 2018, 126, 9-15. [CrossRef]

10. Matveeva, T.N.; Gromova, N.K.; Lantsova, L.B. Analysis of Complexing and Adsorption Properties of Dithiocarbamates Based on Cyclic and Aliphatic Amines for Gold Ore Flotation. J. Min. Sci. 2020, 56, 268-274. [CrossRef]

11. Jian, J.; Guo, Y.; Jiang, L.; An, Y.; Su, J. A Multi-Objective Optimization Model for Green Supply Chain Considering Environmental Benefits. Sustainability 2019, 11, 5911. [CrossRef]

12. Gu, X.; Wang, X.; Liu, Z.; Zha, W.; Xu, X.; Zheng, M. A Multi-Objective Optimization Model Using Improved NSGA-II for Optimizing Metal Mines Production Process. IEEE Access 2020, 8, 28847-28858. [CrossRef]

13. Subramaniam, R.; Ponnusamy, S.K. Novel adsorbent from agricultural waste (cashew NUT shell) for methylene blue dye removal: Optimization by response surface methodology. Water Resour. Ind. 2015, 11, 64-70. [CrossRef]

14. He, K.; Hong, H.; Tang, R.; Wei, J. Analysis of Multi-Objective Optimization of Machining Allowance Distribution and Parameters for Energy Saving Strategy. Sustainability 2020, 12, 638. [CrossRef]

15. Maoz, M.; Ali, S.; Muhammad, N.; Amin, A.; Sohaib, M.; Basit, A.; Ahmad, T. Parametric Optimization of Earth to Air Heat Exchanger Using Response Surface Method. Sustainability 2019, 11, 3186. [CrossRef]

16. Hou, W.-Y.; Li, H.-S.; Li, M.; Cheng, B.-J.; Feng, Y. Effects of electrolysis process parameters on alumina dissolution and their optimization. Trans. Nonferrous. Met. Soc. China 2020, 30, 3390-3403. [CrossRef]

17. Azman, A.R.; Mahat, N.A.; Wahab, R.A.; Ahmad, W.A.; Puspanadan, J.K.; Huri, M.A.M.; Kamaluddin, M.R.; Ismail, D. BoxBehnken design optimisation of a green novel nanobio-based reagent for rapid visualisation of latent fingerprints on wet, non-porous substrates. Biotechnol. Lett. 2021, 43, 881-898. [CrossRef]

18. Huang, R.; Luo, X.; Ji, B.; Wang, P.; Yu, A.; Zhai, Z.; Zhou, J. Multi-objective optimization of a mixed-flow pump impeller using modified NSGA-II algorithm. Sci. China (Technol. Sci.) 2015, 58, 2122-2130. [CrossRef]

19. Deb, K.; Anand, A.; Joshi, D. A Computationally Efficient Evolutionary Algorithm for Real-Parameter Optimization. Evol. Comput. 2002, 10, 371-395. [CrossRef]

20. Liu, B.; Yan, F.; Hu, J.; Turkson, R.F.; Lin, F. Modeling and Multi-Objective Optimization of NOx Conversion Efficiency and NH3 Slip for a Diesel Engine. Sustainablity 2016, 8, 478. [CrossRef]

21. Shojaeefard, M.H.; Zare, J. Modeling and combined application of the modified NSGA-II and TOPSIS to optimize a refrigerant-toair multi-pass louvered fin-and-flat tube condenser. Appl. Therm. Eng. 2016, 103, 212-225. [CrossRef]

22. Han, H.; Yu, R.; Li, B.; Zhang, Y. Multi-objective optimization of corrugated tube inserted with multi-channel twisted tape using RSM and NSGA-II. Appl. Therm. Eng. 2019, 159, 113731. [CrossRef]

23. Zhang, M.; Huang, Q.; Liu, S.; Li, H. Multi-Objective Optimization of Aircraft Taxiing on the Airport Surface with Consideration to Taxiing Conflicts and the Airport Environment. Sustainability 2019, 11, 6728. [CrossRef]

24. Yang, Y.; Li, X.; Han, D. An improved a-cut approach to transforming fuzzy membership function into basic belief assignment. Chin. J. Aeronaut. 2016, 29, 1042-1051. [CrossRef]

25. Zhang, W.; Kumar, M.; Zhou, Y.; Yang, J.; Mao, Y. Analytically derived fuzzy membership functions. Clust. Comput. 2017, 22, 11849-11876. [CrossRef]

26. Zheng, H.; Xing, M.; Cao, T.; Zhang, J. Uncertainty Study and Parameter Optimization of Carbon Footprint Analysis for Fermentation Cylinder. Sustainability 2019, 11, 661. [CrossRef]

27. Ashwni, G.; Faizan, S.A.; Deepak, T. Optimization of cyclic parameters for ORC system using response surface methodology (RSM). Energy Sources Part A Recovery Util. Environ. Eff. 2021, 43, 993-1006.

28. Mohammad, H.E. Thermophysical optimization of ND/PG-water nanofluids by NSGA-II coupled with RSM and ANN. Eur. Phys. J. Plus 2021, 136. [CrossRef]

29. Faheem, K.; Khan, S.U.; Washeem, M. Energy efficient removal of COD from landfill leachate wastewater using electrocoagulation: Parametric optimization using RSM. Int. J. Environ. Sci. Technol. 2021, 1-12. [CrossRef]

30. Ghaleb, A.A.S.; Kutty, S.R.M.; Ho, Y.-C.; Jagaba, A.H.; Noor, A.; Al-Sabaeei, A.M.; Almahbashi, N.M.Y. Response Surface Methodology to Optimize Methane Production from Mesophilic Anaerobic Co-Digestion of Oily-Biological Sludge and Sugarcane Bagasse. Sustainability 2020, 12, 2116. [CrossRef] 